\title{
R11 Avaliação de Novos Insumos e Reagentes para Viabilizar a Conservação do Kit EIE Leishmaniose Canina entre 2 e 80 C
}

Maria Celia Chaves Zuma ${ }^{1}$, Hevandro de Souza Campos ${ }^{1}$, Keila Gisele Azevedo dos Santos ${ }^{1}$, Renata Alves Mota ${ }^{1}$, Cláudia Moraes Molinaro', Nara Mazarakis Rubim¹, Antonio Gomes Pinto Ferreira ${ }^{1}$, Edimilson Domingos da Silva ${ }^{1}$

${ }^{1}$ Bio-Manguinhos, Fiocruz, Rio de Janeiro, RJ

Introdução: A Leishmaniose Visceral Canina (LVC) continua sendo um problema de saúde pública. Esta doença é causada pelo protozoário Leishmania, sendo a Leishmania chagasi responsável por esta infecção no Brasil. Cães domésticos são um dos reservatórios do parasito e quando são picados pelo flebótomo, vetor desta doença, podem infectar os seres humanos. Apesar das medidas de controle, as notificações por Leishmaniose têm aumentado constantemente. O diagnóstico precoce e correto é muito importante, pois ajuda na prevenção e controle da doença. Bio-Manguinhos/Fiocruz-RJ, desde 2004, vem produzindo o conjunto diagnóstico para atender à demanda do Ministério da Saúde. Com a alteração do algoritmo de testagem da Leishmaniose Canina, houve a necessidade da manutenção do fornecimento do teste Elisa que passou a ser usado como confirmatório, sendo imprescindível a otimização nos processos de estocagem e transporte, facilitando a sua utilização pelo usuário final e possibilitando a redução de custos.

Objetivo: Neste estudo testamos reagentes comerciais que possibilitem a armazenagem e o transporte de todo o kit entre 2 e 80 C. Atualmente, parte dos reagentes é mantida a $-200 \mathrm{C}$ e outra sob refrigeração, o que implica em maior complexidade logística tanto de transporte como de estocagem e, consequentemente, maior custo.

Metodologia: Resultados obtidos em ensaios com placas de Elisa sensibilizadas com antígeno de Leishmaniose (L.Major) e mantidas a 200C foram comparados aos obtidos com placas sensibilizadas com o mesmo antígeno e mantidas entre 2 e $80 \mathrm{C}$. Nestas últimas, adicionouse um estabilizante que previne degradação e desnaturação, além de bloquear qualquer sítio livre na superfície da placa, minimizando possíveis reações cruzadas. Para mantermos o conjugado entre 2 e $80 \mathrm{C}$, o mesmo foi diluído $1: 10$ em estabilizante e testado em ensaio imunoenzimático, comparando-se os resultados obtidos com os resultados do conjugado diluído em PBS-glicerol $80 \%$ e mantido a 200C. Para a conservação dos controles positivo e negativo, adicionouse $0,2 \%$ de azida sódica a fim de evitar contaminações no kit mantido entre 2 e 80C. Estes controles foram testados para avaliarmos possíveis interferências da azida sódica e a performance em relação aos mantidos à -200C. 
Resultados: Testes de equivalência foram realizados e as placas de Elisa mantidas entre 2 e $80 \mathrm{C}$ apresentaram mesmo índice de reatividade que as placas congeladas. $O$ conjugado se manteve estável, com o mesmo título encontrado no início do estudo, apresentando mesmo índice de reatividade. A utilização da azida sódica nos soros controle positivo e negativo foi satisfatória. Os mesmos não apresentaram alteração de título e não houve interferência com a peroxidase, possibilitando mantê-los entre 2 e $80 \mathrm{C}$.

Conclusão: Este estudo demonstra a viabilidade da modificação da temperatura de estocagem dos insumos integrantes do kit EIE Leishmaniose Visceral Canina, de $-200 \mathrm{C}$ para 2 a $80 \mathrm{C}$, uma vez que não foi observada alteração das condições e desempenho do teste.

Palavras-Chave: Leishmaniose Canina, Diagnóstico 